\title{
Dynamics of Short and Long Term Debt Market Integration in the South Asian Economies
}

\author{
Sanjay Sehgal1, Piyush Pandey², Sakshi Saini' ${ }^{1}$ \\ ${ }^{1}$ Department of Financial Studies, University of Delhi, Delhi, India \\ ${ }^{2}$ FORE School of Management, B-18, Qutub Institutional Area, Delhi, India \\ Email: s.sakshi1408@gmail.com
}

How to cite this paper: Sehgal, S., Pandey, P. and Saini, S. (2018) Dynamics of Short and Long Term Debt Market Integration in the South Asian Economies. Theoretical Economics Letters, 8, 2416-2443. https://doi.org/10.4236/tel.2018.811157

Received: June 25, 2018

Accepted: August 19, 2018

Published: August 22, 2018

Copyright ( 92018 by authors and Scientific Research Publishing Inc. This work is licensed under the Creative Commons Attribution International License (CC BY 4.0).

http://creativecommons.org/licenses/by/4.0/

(c) (i) Open Access

\begin{abstract}
We investigate the extent of financial integration in both short and long term government debt markets of five South Asian economies from January 2004 to May 2016. We employ copula functions and find weak dependencies in their short and long term debt markets. We supplement our analysis using Diebold and Yilmaz spillover index and find low level of return spillover across both short and long term debt markets, thereby reconfirming low level of financial integration in the debt markets of the region. Linkages between short and long term debt markets are also weak suggesting underdeveloped nature of these markets.
\end{abstract}

\section{Keywords}

Short Term Debt Market Integration, Long Term Debt Market Integration, South Asia, Time Varying Copula, Diebold and Yilmaz

\section{Introduction}

Ever since the Asian Financial Crisis struck the Asian economies in 1997, there has been a growing consensus on the need for a well-developed debt market as a critical segment of an economy's financial system. Domestic debt market is important for capital allocation and risk management, and provides avenues for financing long term investment. One of the reasons why financial system of the Asian economies suffered major setback during the crisis was due to its excessive reliance on the banking sector without institutional safeguards at place. Existence of a robust and well-developed debt market would have insulated these economies from exposure to maturity mismatches that typically ensued from short term debt being raised for long term investment purposes, and thus would have mitigated the impact of financial turmoil. Having realised the weaknesses 
of a bank-centred financial system, East Asian economies began efforts in the aftermath of crisis to develop efficient and liquid debt market that manifested into the Asian Bond Market Initiative (ABMI) ${ }^{1}$ to foster high degree of development and integration of the bond markets of the region. While the East Asian economies had detrimental impact on their financial systems from the fallout of crisis, South Asian economies ${ }^{2}$ remained resilient to it perhaps due to their isolated and underdeveloped financial markets. Nevertheless, with the changing global economic landscape, South Asian countries have altered their economic policy paradigm since early 1990s towards more liberalized economic and financial systems that were earlier shackled with protectionist trade policies and strict capital controls. Therefore, in the midst of increased globalization, the repercussions of any adverse global shock on these economies that may arise in future will not be escapable especially if they do not focus on broadening and deepening their financial structures. South Asian economies, however, happen to neglect lessons from the previous episode of Asian crisis. With the gradual reforms in financial markets, these countries have largely become bank-centric and equity-oriented, but development of deep and broad debt market has not been emphasized yet. This is reflected in the size of South Asian banking system (measured as amount of deposits) being equivalent on an average to $57 \%$ of GDP and stock market capitalization $60.3 \%$ of GDP, while the public debt outstanding is only worth $27 \%$ of GDP [1].

In the South Asian region, only India has deep and liquid debt market. Debt markets in rest of the South Asian countries are at nascent stages and the progress in their development is lagging behind. This is reflected in the level of short and long term debt inflows into the SAARC region amounting to USD 23 billion and 77 billion respectively in 2015, which are low as compared its ASEAN counterpart with inflows amounting to USD 36bn for short-term debt and USD 252bn for long-term debt ${ }^{3}$. Much of the short and long term debt inflows into South Asia are concentrated in India. Figure 1 clearly depicts that debt flows into India have risen overwhelmingly in the last decade, while other South Asian countries have attracted a meagre amount of short and long term debt inflows. The development of the debt market in these countries is hindered due to several factors like absence of price mechanisms in the allocation of funds, small institutional investors' base, lack of necessary infrastructures like clearing and settlement system and complex legal and regulatory framework.

Development and integration of debt markets are not just important for financial stability of the region, but also have several implications for both investors and policymakers. It helps in understanding the conduct of monetary policy,

\footnotetext{
${ }^{1}$ Asian Bond Market Initiative (ABMI) is an initiative of Association of South East Asian Nations Plus Three (ASEAN + 3) that includes 10 members of ASEAN plus the People's Republic of China, Japan and South Korea. This initiative was put in place in 2003.

${ }^{2}$ South Asian economies are the eight countries of South Asian region: Afghanistan, Bangladesh, Bhutan, India, Maldives, Nepal, Pakistan and Sri Lanka.

${ }^{3}$ Source: IMF CPIS, Authors' Calculations.
} 


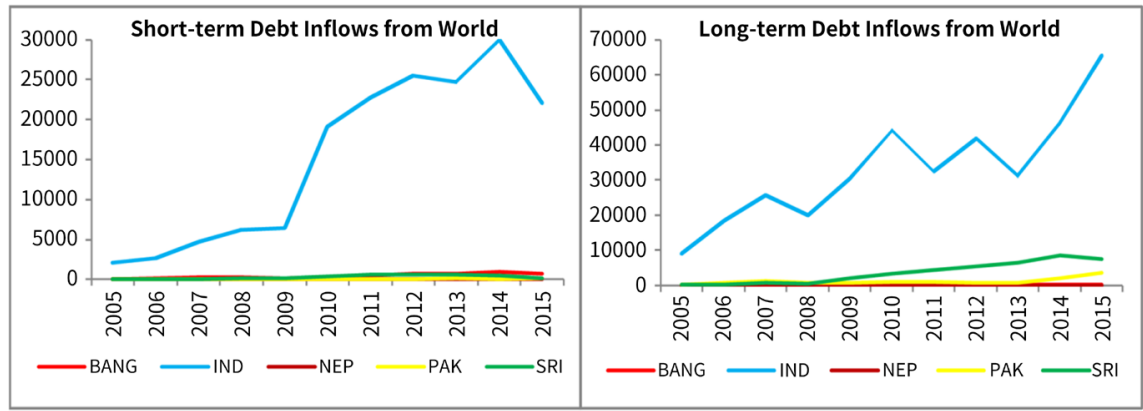

Figure 1. Short and long term debt inflows into South Asian countries from the World. Notes: 1) All figures are end of the period and in USD millions; 2) BANG, IND, NEP, PAK and SRI denote Bangladesh, India, Nepal, Pakistan and Sri Lanka, respectively. Source: IMF CPIS, Authors' Calculations.

strategizing portfolio diversification, modelling and forecasting interest rates and estimating cost of financing fiscal deficit [2]. Thus, a closer inspection on the debt markets of the region and their inter linkages is warranted. We primarily focus on South Asian region for several important reasons. According to World Bank [3], it is one of the fastest growing regions in the world with its growth estimated at 7 percent in 2015 which is more than twice the global economic growth ${ }^{4}$, and is projected to increase to 7.6 percent in 2017. The region, therefore, provides attractive investment propositions with huge diversification potential to the international investors. Further, the region has the world's largest working age population, a quarter of the world's middle-class consumers, the largest number of poor and undernourished in the world, and several fragile states of global geopolitical importance [4], signifying immense opportunities that can act as a recourse to harness its enormous potential. Globally, the region is gaining significance as indicated by the list of its observer countries ${ }^{5}$ that are engaged in collaborative ventures of South Asian Association for Regional Cooperation (SAARC) ${ }^{6}$. Given that South Asian region is becoming increasingly connected to the global financial system, it needs to emphasize development and integration of its debt markets to reduce financial fragility arising from an external shock and subsequent recession that may hamper its strong growth prospects.

We use both short and long term debt returns to examine the level of integration in South Asian economies. This is so because the degree of integration across countries at the extreme ends of debt maturity spectrum is expected to differ as the underlying factors that govern short and long end are distinct [5] [6]. It is envisaged that synchronization of monetary policies and business cycles across countries would lead to integration of the short term debt markets, while

${ }^{4} \mathrm{Global}$ economic growth is estimated at 3.1 percent in 2015 and is projected at 3.6 percent in 2017 (World Economic Outlook, IMF).

${ }^{5}$ SAARC has nine observers: Australia, China, European Union, Iran, Japan, Republic of Korea, Mauritius, Myanmar and the United States.

${ }^{6}$ Formed in 1985, SAARC is a regional economic block of all eight South Asian countries: Afghanistan, Bangladesh, Bhutan, India, Maldives, Nepal, Pakistan and Sri Lanka. 
being less relevant to long term debt market integration. This is due to the fact that short term debt yields change in response to the policy of monetary authority; on the other hand long term debt yields are driven by investors' preferences, saving and investment climate, risk appetite, and expectations. Given this, it is worthwhile to investigate the level of integration across the short term as well as long term debt markets of South Asian countries. We further examine the degree of integration between short and long end of the yield curve within the economies as it has important implications for understanding the term structure of interest rates. For instance, high integration between the short and long term debt markets would presumably be because of common factors driving debt returns at the two ends of maturity spectrum, whereas, lack of integration would suggest market segmentation based on maturity.

Thus, the present study seeks to fulfil following objectives: 1) it assesses the level of short term debt market integration amongst five South Asian countries (Bangladesh, India, Nepal Pakistan and Sri Lanka), 2) evaluates the degree of integration amongst the long term government debt markets of the sample countries, 3) examines the level of association amongst the short and long term debt markets within each sample country. We employ copula models to empirically assess dynamic interdependencies of short and long term debt markets across and within these economies from January 2004 to May 2016. We further supplement our analysis with Diebold and Yilmaz [7] spillover index methodology to disentangle the level and direction of interconnectedness of the short/long term debt markets across these countries. Our analysis is focused on five South Asian economies (Bangladesh, India, Nepal Pakistan and Sri Lanka) of the SAARC region because of the paucity of data for rest of the South Asian countries. We make substantial contributions to the financial integration literature by studying the South Asian debt markets that have not been previously studied and provide policy suggestions for strengthening the level of debt market integration amongst them.

The remainder of the paper is structured as follows: Section 2 presents the data, and Section 3 lays out the methodology. Section 4 presents the empirical results and Section 5 contains summary and policy suggestions.

\section{Review of Literature}

While European debt markets have garnered ample academic attention [2] [6] [8]-[18], only a few studies have examined the extent of debt market integration in the Asian region probably because most of the debt markets of the region are still at nascent stage. Vo [19] assesses the degree of financial integration in Asian bond markets and reports low degree of interdependencies among them. Rughoo and You [20] examine bond market integration in Southeast Asia and find them to be globally as well as regionally integrated. Sowmya, Prasanna and Bhaduri [21] investigate linkages in the sovereign bond yields across different maturity spectrum among the Asian countries and find high spillover across the 
countries. Surprisingly, debt market integration of South Asian region has been overlooked by the researchers in the whole gamut of financial integration literature. Hence, in this paper we examine the extent of debt market integration specifically focusing on the South Asian economies, research on which is virtually untouched.

Early contributions to the literature on debt market integration have employed Vector Error Correction Models (VECM) and causality tests to investigate the long and short run linkages among the government bond returns [9] [19] [22]. A range of studies have also examined the degree of integration among the bond markets using government bond risk premiums by applying International Capital Asset Pricing Model (CAPM) based on the work of Bekaert anf Harvey [23]. For example, see [2] [10] [12] [18] [24]. Several other techniques like variance decomposition analysis [25], generalized impulse response analysis [15], Phillips and Sul convergence [20] have been used to investigate the degree of financial integration among the bond markets. Econometric techniques have evolved overtime into more advanced time-series approaches to analyse the time-varying conditional correlations. Recent studies have used multivariate GARCH models [26] [27] [28] or realised correlations approach [14] to analyse time-varying conditional co-movements of the bond markets. Copula-based models have emerged lately to examine non-linear structural dependencies among the markets [29] [30]. These models capture dependency structures by modelling multivariate distributions and address non-normality and non-elliptical distributions. Such models are thus suitable to assess time-varying conditional correlations of financial asset returns that exhibit complexities in terms of asymmetry or/and fat tails. Literature has also applied these models to study the structural dependencies among the government bond markets $[5]^{7}$ $[6]^{8}$.

\section{Methodology and Data}

\subsection{Copulas}

Pearson's correlation is the traditional approach to examine dependence between the random variables. However, dependence between financial assets cannot be captured by a linear measure of association which is based upon the assumption of multivariate normality [31] [32] [33]. Copula functions model dependence beyond linear correlation and provide a high degree of flexibility in specifying a multivariate distribution [29] [34]. Based upon the Sklar Theorem [35], they decompose multivariate distributions into their univariate marginal functions and are able to capture asymmetry and tail dependence that financial assets often exhibit. Further, copula functions not only estimate the degree of ${ }^{7}$ Kumar and Okimoto [5] employ smooth transition copula-GARCH model to investigate correlation dynamics among the G7 bond markets and find marked increase in the government bond market integration of these economies over the years.

${ }^{8}$ Yang and Hamori [6] examine structural dependence amongst the bond markets of Poland, the Czech Republic and Hungary with that of Germany and document decreased integration among them during the global financial crisis. 
dependence but also the structure of dependence and hence provide valuable insights about the extent of diversification benefits [36]. While the dependence structure in a multivariate GARCH framework (DCC GARCH, ADCC GARCH, etc.) relies on marginal distribution, copula separates the dependence structure from the choice of margins thereby making this approach more robust and favourable [37]. Time-varying conditional copula functions, pioneered by Patton [29], help in capturing the dependence structure overtime. Conditional copula function $C_{t}\left(U_{\text {countryi, },}, U_{\text {country } j, t} \mid \phi_{t-1}\right)$ can be written using the two time varying cumulative distributive functions. Extending Sklar's theorem, bivariate conditional cumulative distributive function of random variable $R_{\text {country } i, t}$ and $R_{\text {countryj }, t}$ is:

$$
F\left(R_{\text {country }, t}, R_{\text {country } j, t} \mid \phi_{t-1}\right)=C_{t}\left(U_{\text {country } i, t}, U_{\text {country } j, t} \mid \phi_{t-1}\right)
$$

where, $R_{\text {countryi,t }}$ and $R_{\text {countryj, } t}$ are the random variables that denote country is debt returns and country $j$ s debt returns respectively at period $t$, with marginal conditional cumulative distribution function $U_{\text {countryi,t }}=G_{\text {country } i, t}\left(R_{\text {country }, t} \mid \phi_{t-1}\right)$ and $U_{\text {countryj, }, t}=G_{\text {country }, t}\left(R_{\text {country }, t} \mid \phi_{t-1}\right), \phi_{t-1}$ denotes past information.

The dependence structure among the debt returns of South Asian countries is examined undertaking four steps: First, we apply AR $(1)$-EGARC $(1,1)$ model to compute the marginal distribution of the return series and obtain their standardized residuals. Second, we transform standardized residuals into uniform distribution that are i.i.d (independently and identically distributed) and model the dependence structure using Elliptical and Archimedean family of copulas. In the third step, we determine the parameter of copula functions by employing Inference Function for Margin (IFM) method. Finally, we evaluate the goodness of fit of the copula models.

\subsubsection{Marginal Specification}

We employ Autoregressive (AR) and Generalized Autoregressive Conditional Heteroscedasticity (GARCH) framework to model the marginal distribution of debt return series. EGARCH model [38] allows us to capture asymmetries in positive and negative shocks and puts no restriction on the GARCH parameters; hence we fit this model of conditional heteroskedasticity with conditional copula functions to capture the stylized characteristics of asset returns. We adopt AR (1) and EGARCH $(1,1)$ model in the interest of parsimony of parameters [39].

The mean equation used for country $i$ s returns is as follows:

$$
R_{\text {country }, t}=\mu+R_{\text {country }, t-1}+R_{\text {usa }, t-1}+\varepsilon_{t}
$$

If $\varepsilon_{t}=\sigma_{t} z_{t}$ where $z_{t}$ is standard Gaussian, then $\operatorname{EGARCH}(1,1)$ :

$$
\ln \left(\sigma_{t}^{2}\right)=\omega+\alpha\left(\left|z_{t-1}\right|-E\left[\left|z_{t-1}\right|\right]\right)+\Upsilon z_{t-1}+\beta \ln \left(\sigma_{t-1}^{2}\right)
$$

Here, $R_{\text {usa }}$ is the short/long term debt return of the USA and is used as a global factor. We incorporate lagged US debt returns as a proxy for global spillover effects in mean equation so as to capture the effect of global market volatility on 
the domestic debt market. Financial asset return series generally tend to exhibit non-normal and heavy tail behavior [40]. Hence, to accommodate the heavy tail of residuals in GARCH framework, conditional Student-t distribution as suggested by Bollerslev [41] is used.

\subsubsection{Copula Models for Dependence}

We now proceed with the standardized residuals obtained from the marginal specification, which are converted to uniform distributions using probability integral transform. To model the dependence structure between debt returns, we consider Elliptical (Gaussian and Student-t) copulas that are symmetric in nature and Archimedean (Clayton and Gumbel) copulas that allow for asymmetry (in upper and lower tail dependence, respectively) and flexibility in modeling dependencies. Further, we estimate time-invariant and time variant copula models to examine both time invariant and time varying nature of dependencies among debt returns.

Time Invariant Copula Models

1) Gaussian Copula: Following [29], the dependence parameter of Gaussian process is

$$
\begin{aligned}
C_{G a}(u, v ; \rho) & =\int_{-\infty}^{\phi^{-1}(u)} \int_{-\infty}^{\phi^{-1}(v)} \frac{1}{2 \pi \sqrt{1-p^{2}}} \exp \left(-\frac{x_{1}^{2}-2 \rho x_{1} x_{2}+x_{2}^{2}}{2\left(1-\rho^{2}\right)}\right) \mathrm{d} x_{1} \mathrm{~d} x_{2} \\
& =\phi_{p}\left(\phi^{-1}(u), \phi^{-1}(v) ; \rho\right)
\end{aligned}
$$

where $u$ and $v$ are cumulative distribution functions of standardized residuals, subjected to a uniform distribution between 0 and 1, $\rho$ is Pearson's linear correlation, $\phi^{-1}$ is the inverse cumulative distribution function of a standard normal distribution.

2) T-Copula: The dependence parameter of $t$ copula follows from [42]:

$$
\begin{gathered}
C(u, v)=\int_{-\infty}^{T_{v}^{-1}(u)} \mathrm{d} x \int_{-\infty}^{T_{v}^{-1}(v)} \mathrm{d} y \frac{1}{2 \pi \sqrt{1-p^{2}}}\left[1+\frac{x^{2}-2 \rho x y+y^{2}}{v\left(1-\rho^{2}\right)}\right]^{-\frac{v+2}{2}} \\
T_{v}(x)=\int_{-\infty}^{x} \frac{\Gamma\left(\frac{v+1}{2}\right)}{\sqrt{\pi v} \Gamma\left(\frac{v}{2}\right)}\left(1+\frac{z^{2}}{v}\right)^{-\frac{v+1}{2}} \mathrm{~d} z
\end{gathered}
$$

$T$ is the student $t$ distribution with degrees of freedom $V$ and Pearson's correlation $\rho$. In comparison to Gaussian copula, $\mathrm{t}$ copula captures the tail dependence.

3) Gumbel Copula: The dependence parameter [43] which can capture the upper tail dependence:

$$
C_{G a}(u, v ; \theta)=\exp \left(-\left((-\ln u)^{\theta}+(-\ln v)^{\theta}\right)^{\frac{1}{\theta}}\right)
$$

where $1 \leq \theta<+\infty$; upper limit in Gumbel copula is $\infty$. 
4) Clayton Copula: The dependence parameter [44] captures the lower tail dependence:

$$
C_{C L}(u, v ; \theta)=\left(u^{-\theta}+v^{-\theta}-1\right)^{-1 / \theta}
$$

where $0 \leq \theta<+\infty$;

Time Varying Copula Models

Time varying copulas can be considered as dynamic generalization of a Pearson correlation or Kendall's tau but it is difficult to find causal variables to explain such characteristics [29] [45]. In practice though, time varying copulas are operationalized to follow autoregressive moving average (ARIMA) $(p, q)$ process.

1) Time varying Gaussian Copula [46] uses a coefficient $\rho_{t}$ to study the dependence dynamics defined as:

$$
\rho_{t}=\tilde{\Lambda}\left(\omega_{N}+\beta_{N 1} \cdot \rho_{t-1}+\cdots+\beta_{N p} \cdot \rho_{t-p}+\alpha_{N} \cdot \frac{1}{q} \sum_{j=1}^{q} \phi^{-1} v_{t-j}\right)
$$

where $\tilde{\Lambda}(x)$ is a logistic transformation which is defined as $\tilde{\Lambda}(x)=\left(1-\mathrm{e}^{-x}\right)\left(1-\mathrm{e}^{-x}\right)^{-1}$.

2) Time varying $T$ copula [47] uses the following to study the dependence process:

3) $\rho_{t}=\tilde{\Lambda}\left(\omega_{T}+\beta_{T 1} \cdot \rho_{t-1}+\cdots+\beta_{T p} \cdot \rho_{t-p}+\alpha_{T} \cdot \frac{1}{q} \sum_{j=1}^{q} T^{-1}\left(u_{t-j} ; D o F\right) \cdot T^{-1}\left(v_{t-j} ; D o F\right)\right)$ where $T^{-1}$ is the inverse function of the student $\mathrm{t}$-distribution with given degrees of freedom $(D o F)$.

4) Time varying Gumbel copula studies the dependence using $\theta_{t}$ corresponding to $\tau_{t}=1-1 / \theta_{t}$ defined as:

$$
\tau_{t}=\Lambda\left(\omega_{G}+\beta_{G 1} \cdot \tau_{t-1}+\cdots+\beta_{G p} \cdot \tau_{t-P}+\alpha_{G} \cdot \frac{1}{q} \sum_{j=1}^{q}\left|u_{t-j}-v_{t-j}\right|\right)
$$

where $\Lambda(x)=\left(1+\mathrm{e}^{-x}\right)^{-1}$.

5) Time varying Clayton copula uses $\theta_{t}$ corresponding to $\tau_{t}=\theta_{t} /\left(2+\theta_{t}\right)$ to find the dependence defined as:

$$
\tau_{t}=\Lambda\left(\omega_{C}+\beta_{C 1} \cdot \tau_{t-1}+\cdots+\beta_{C p} \cdot \tau_{t-P}+\alpha_{C 1} \cdot\left|u_{t-1}-v_{t-1}\right|+\cdots+\alpha_{C q} \cdot\left|u_{t-q}-v_{t-q}\right|\right)
$$

\subsubsection{Estimation of Copula Parameters}

Parameters are normally estimated in two steps, first for the marginal and second for the copula. The approach is similar to the Inference function for Margin (IFM) method. IFM method is superior to Exact Maximum Likelihood (EML) as the latter needs expensive computation more so for higher dimensions. In IFM method, parameters of the marginal distributions can be estimated before those of the copula functions whereas the EML method requires both to be estimated simultaneously. 


\subsubsection{Goodness of Fit Tests}

Besides the log likelihood ratios, in order to check the quality of the overall fit of the family of copula models, goodness of fit test of [48] which is based on a comparison of the distance between the estimated and the empirical copula:

$$
C_{n}=\sqrt{n}\left(C_{n}-C_{\theta_{n}}\right) .
$$

The test statistic is based on Cramer-Von Mises distances defined as:

$$
S_{n}=\int C_{n}(u)^{2} \mathrm{~d} C_{n}(u)
$$

Large values of the statistic $S_{n}$ leads to rejection of the null hypothesis that the Copula $C$ belongs to the class $C_{0}$. A multiplier approach is used to find the $\mathrm{p}$-values associated with the test statistics [46]. The highest p-value indicates that the distance between the empirical and the estimated copulas is the smallest and that the copula in use provides the best fit [47].

\subsection{Diebold and Yilmaz Methodology}

We employ spillover index proposed by Diebold and Yilmaz [7] to measure interlinkages among the South Asian debt markets. This methodology allows us to decompose shocks from each country using generalized vector autoregressive (VAR) framework [48] [49]. The spillover index is constructed by aggregating the contribution of forecast error variance of variable $i(i=1, \cdots, N)$ to that of variable $j(j=1, \cdots, N)$, for all $i \neq j$. N-variable VAR of order $\mathrm{p}$ can be written as:

$$
x_{t}=\sum_{i=1}^{p} \phi_{i} x_{t-i}+\varepsilon_{t}
$$

where $\varepsilon_{t}$ is the variance of the error terms which are independently and identically distributed. It can be also written in moving average form as $x_{t}=\sum_{i=1}^{\infty} A_{i} \varepsilon_{t-i}$ where $A_{i}=\sum \phi_{j} A_{i-j}$ and $j=1, \cdots, p$. The $H$ step ahead forecast error variance decomposition $\left(\theta_{i j}^{g}(H)\right)$ is defined as follows:

$$
\theta_{i j}^{g}(H)=\frac{\sigma_{i i}^{-1} \sum_{h=0}^{H-1}\left(e_{i}^{\prime} A_{h} \Sigma e_{j}\right)^{2}}{\sum_{h=0}^{H-1}\left(e_{i}^{\prime} A_{h} \Sigma A_{h}^{\prime} e_{j}\right)}
$$

where $\Sigma$ is the variance matrix for the error term of VAR, $\sigma_{i j}$ is the standard deviation of the error term for the th equation and $e_{i}$ is the selection vector with one for the th element and zero otherwise. Each forecast error variance decomposition is normalized by the row sum as:

$$
\tilde{\theta}_{i j}^{g}(H)=\frac{\theta_{i j}^{g}(H)}{\sum_{j=1}^{N} \theta_{i j}^{g}(H)}
$$

Total Connectedness is the summation of cross-variance shares, which are the fraction of the $H$ step ahead error variances in forecasting $X_{i}$ due to shocks to $X_{j}$. Directional Connectedness is a measure of the connectedness that captures the shocks received by vector i from all other vectors $j$ and vice versa. Finally, the difference between the shocks transmitted to and shocks transmitted from all other markets provides the measure of Net Connectedness. 


\subsection{Data}

The data comprises of 91-day (13-week) Treasury bill yield and 10-year government securities yield (shown in Figure 2) as a proxy for short-term and long-term debt yield, respectively for five South Asian countries: Bangladesh, India, Nepal, Pakistan and Sri Lanka, and the USA (used as global factor). 91-day treasury yields of Bangladesh, Pakistan and Sri Lanka are retrieved from CEIC, whereas those of India, Nepal and the USA are obtained from their respective Central Bank's database. Data for 10-year government securities yields for all countries is obtained from Bloomberg. We begin our analysis from January 2004 as South Asian Free Trade Area (SAFTA) was signed in this month and it de facto became the most important initiative of the SAARC countries in strengthening regional cooperation and integration. Hence we obtain debt yields from January 2004 to May 2016 for all sample countries. The only exception is Bangladesh, as the short-term and long-term debt yields are available from August 2004 and November 2006 onwards, respectively. The analysis of all eight SAARC member countries is not possible because of the unavailability of both short-term and long-term debt yield data for Afghanistan, Bhutan and Maldives. Also, owing to the paucity of data we take monthly data sampled on the end of each month with proximal data points interpolated in case of missing data. Short and long term debt returns for the sample countries are computed on the basis of formula used by Abad, Chuliá and Gómez-Puig [2] in calculating bond returns for a sample of European countries, and are used for subsequent analysis in the paper. The returns are defined as:

$$
R_{i t}=n\left(y_{i t-1}-y_{i t}\right)
$$

where, $R_{i t}$ denotes returns on bonds, $n$ denotes the maturity of bonds, and $y_{i t}$ is the natural logarithm of gross yield to maturity i.e. $y_{i t}=\ln \left(1+Y_{i t}\right), Y_{i t}$ denotes the bond yields.

\section{Results}

\subsection{Preliminary Analysis}

Table 1 (a) and Table 1 (b) report the summary statistics of monthly short term

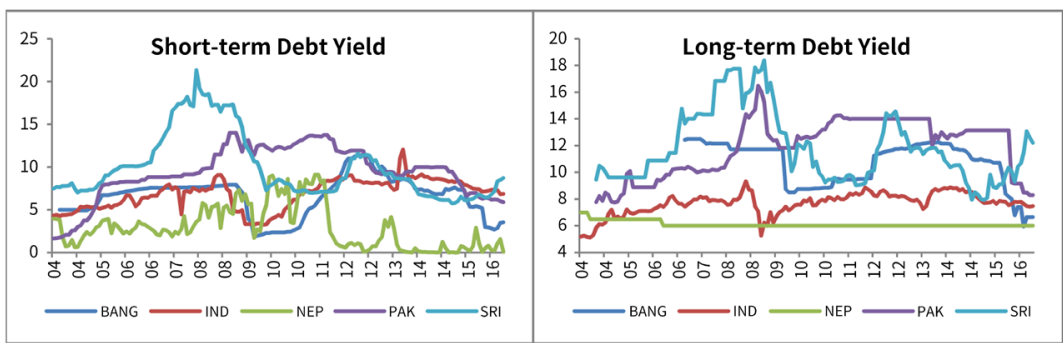

Figure 2. Short and long term debt yields of South Asian countries. Notes: 1) BANG, IND, NEP, PAK and SRI denote Bangladesh, India, Nepal, Pakistan and Sri Lanka, respectively; 2) 91 day Treasury bill yield and 10 year government securities yield are taken as a proxy for short-term and long-term debt yield, respectively. Source: CEIC, Bloomberg, Central Bank Website. 
Table 1. (a): Descriptive Statistics of short-term and long-term debt return series of sample countries; (b): Descriptive Statistics of long term debt return series of sample countries.

(a)

\begin{tabular}{|c|c|c|c|c|c|c|c|c|c|c|}
\hline Countries & s Mean & Std. Dev. & $\operatorname{Max}$ & Min & Skew & Kurt & JB & LB & $\begin{array}{c}\mathrm{ARCH} \\
\mathrm{LM}\end{array}$ & Obsv \\
\hline BANG & 0.0010 & 0.0210 & 0.1155 & -0.0452 & 3.43 & 19.72 & $\begin{array}{c}1605.17^{\star *} \\
{[0.00]}\end{array}$ & $\begin{array}{l}23.47 \\
{[0.02]}\end{array}$ & $\begin{array}{c}0.04 \\
{[0.84]}\end{array}$ & 118 \\
\hline IND & -0.0007 & 0.0199 & 0.1075 & -0.0986 & 0.61 & 16.35 & $\begin{array}{c}1116.43^{\star *} \\
{[0.00]}\end{array}$ & $\begin{array}{c}3.68 \\
{[0.98]}\end{array}$ & $\begin{array}{c}12.63^{\star *} \\
{[0.00]}\end{array}$ & 149 \\
\hline NEP & 0.0025 & 0.0725 & 0.2257 & -0.2017 & 0.42 & 4.10 & $\begin{array}{c}11.94^{* *} \\
{[0.00]}\end{array}$ & $\begin{array}{c}29.53^{\star \star} \\
{[0.00]}\end{array}$ & $\begin{array}{c}2.69 \\
{[0.10]}\end{array}$ & 149 \\
\hline PAK & -0.0016 & 0.0110 & 0.0291 & -0.0540 & -1.18 & 7.52 & $\begin{array}{c}161.32^{\star *} \\
{[0.00]}\end{array}$ & $\begin{array}{c}107.09^{* *} \\
{[0.00]}\end{array}$ & $\begin{array}{l}8.54^{* *} \\
{[0.00]}\end{array}$ & 149 \\
\hline SRI & -0.0003 & 0.0118 & 0.0353 & -0.0526 & -0.40 & 6.14 & $\begin{array}{c}65.38^{* *} \\
{[0.00]}\end{array}$ & $\begin{array}{c}44.94^{* *} \\
{[0.00]}\end{array}$ & $\begin{array}{l}4.61^{* *} \\
{[0.03]}\end{array}$ & 149 \\
\hline
\end{tabular}

Notes: The table displays summary statistics for the daily returns over the period from January 2004 to May 2016. 1) ${ }^{* *}$ denotes level of significance at 5\%. Values in parentheses [ ] indicate the p-values; 2) Stdev = Standard Deviation, Skew $=$ Skewness, Kurt $=$ Kurtosis, JB $=$ JarqueBera, $\mathrm{LB}=$ Ljung Box. LB statistics for serial correlation is reported up to 12 lags; 3). BANG, IND, MALD, NEP, PAK and SRI denote Bangladesh, India, Maldives, Nepal, Pakistan and Sri Lanka respectively; 4) Source: 91-day treasury yields of Bangladesh, Pakistan and Sri Lanka retrieved from CEIC, whereas those of India and Nepal are obtained from their respective Central Bank's database.

(b)

\begin{tabular}{|c|c|c|c|c|c|c|c|c|c|c|}
\hline Countries & Mean & Std. Dev. & $\operatorname{Max}$ & Min & Skew & Kurt & JB & LB & ARCH LM & Obsv \\
\hline BANG & 0.0495 & 0.4193 & 2.6693 & -1.4940 & 2.94 & 21.19 & $\begin{array}{c}1736.75^{* *} \\
{[0.00]}\end{array}$ & $\begin{array}{l}11.94 \\
{[0.45]}\end{array}$ & $\begin{array}{c}0.17 \\
{[0.68]}\end{array}$ & 114 \\
\hline IND & -0.0217 & 0.4039 & 2.5475 & -1.4671 & 1.43 & 14.98 & $\begin{array}{c}941.19^{* *} \\
{[0.00]}\end{array}$ & $\begin{array}{r}38.27^{* *} \\
{[0.00]}\end{array}$ & $\begin{array}{c}13.15^{* *} \\
{[0.00]}\end{array}$ & 149 \\
\hline NEP & 0.0090 & 0.0771 & 0.6899 & 0.0000 & 8.47 & 72.85 & $\begin{array}{c}32069.81^{* *} \\
{[0.00]}\end{array}$ & $\begin{array}{c}0.17 \\
{[0.99]}\end{array}$ & $\begin{array}{c}0.03 \\
{[0.87]}\end{array}$ & 149 \\
\hline PAK & -0.0040 & 0.4289 & 3.2222 & -1.4807 & 3.23 & 26.94 & $\begin{array}{c}3663.11^{* *} \\
{[0.00]}\end{array}$ & $\begin{array}{c}5.85 \\
{[0.92]}\end{array}$ & $\begin{array}{c}0.05 \\
{[0.83]}\end{array}$ & 143 \\
\hline SRI & -0.0162 & 0.5401 & 1.7245 & -1.7312 & -0.12 & 4.72 & $\begin{array}{c}18.01^{* *} \\
{[0.00]}\end{array}$ & $\begin{array}{c}9.85 \\
{[0.63]}\end{array}$ & $\begin{array}{c}0.28 \\
{[0.59]}\end{array}$ & 143 \\
\hline
\end{tabular}

Notes: Panel A and B of the table displays summary statistics for short term and long term debt return series, respectively. 1) ${ }^{* *}$ denotes level of significance at $5 \%$. Values in parentheses [ ] indicate the p-values; 2) Stdev $=$ Standard Deviation, Skew $=$ Skewness, Kurt $=$ Kurtosis, JB $=$ JarqueBera, LB $=$ Ljung Box. LB statistics for serial correlation is reported up to 12 lags; 3) BANG, IND, MALD, NEP, PAK and SRI denote Bangladesh, India, Maldives, Nepal, Pakistan and Sri Lanka respectively; 4) Source: 91-day treasury yields (short-term debt yields) of Bangladesh, Pakistan and Sri Lanka retrieved from CEIC, whereas those of India and Nepal are obtained from their respective Central Bank's database. 10-year government securities yields (long-term debt yields) are obtained from Bloomberg.

and long term debt return series, respectively of five South Asian countries included in our study. The short-term and long-term average debt returns for all South Asian countries are extremely low and even negligible for majority of them. Contrary to the general conviction, long-term debt markets exhibit high volatility as compared to that of short-term as indicated by standard deviation which is much higher for long-term government securities. Skewness coefficient 
is positive and kurtosis is high for majority of the debt return series, indicating fat tails and sharp peaks. Normality of the return distribution is therefore rejected by Jarque-Bera test statistic which is statistically significant for all the cases. Results of Ljung-Box Q-statistic (of order 12) and ARCH LM test indicate that only the long-term debt return series of India exhibit serial correlation and heteroscedasticity. Whereas, the short-term debt return series for all South Asian countries except India are serially correlated. ARCH effect is displayed by the short-term return series of India, Pakistan and Sri Lanka. We also conduct Augmented Dicky-Fuller [50], KPSS [51] and Phillips-Perron [52] tests of stationarity as a precursor to time series analysis and find all sample debt return series to be integrated at level.

\subsection{Estimation Results of Copula Models}

Since evidence of heteroscedasticity is found in the short-term debt return series of India, Pakistan and Sri Lanka and long-term debt return series of India, we model marginal distribution of these series using $\operatorname{EGARCH}(1,1)$ process with Student-t distribution which is appropriate to capture fat tails. We model marginal distribution for rest of the series using AR (1) model.

The results of marginal model for short term and long term debt return series are presented in Table 2(a) and Table 2(b), respectively. Short term debt returns of India and Bangladesh are sensitive to the spillovers from the global market as indicated by significant value of the coefficient of lagged US debt return. Amongst the long term debt markets, international spillover effect is

Table 2. (a): Results of the Marginal Specification of short term debt return series of Sample Countries; (b): Results of the Marginal Specification of long term debt return series of Sample Countries.

(a)

\begin{tabular}{cccccccc}
\hline \multicolumn{3}{c}{ Mean Eqn } & \multicolumn{5}{c}{ Variance Eqn } \\
\hline Country & $\boldsymbol{\mu}$ & $\boldsymbol{R}_{\text {country I }}(-1)$ & $\boldsymbol{R}_{\mathrm{USA}}(-1)$ & $\boldsymbol{\omega}$ & $\boldsymbol{\alpha}$ & $\boldsymbol{\gamma}$ & $\boldsymbol{\beta}$ \\
\hline \multirow{2}{*}{ BANG } & 0.0010 & $0.2410^{* *}$ & -0.1800 & - & - & - & - \\
& $(0.00)$ & $(0.09)$ & $(0.10)$ & & & & \\
& -0.0007 & $0.1102^{* *}$ & $0.0973^{* *}$ & -0.7140 & 17.7858 & 9.7858 & 0.1290 \\
IND & $(0.00)$ & $(0.05)$ & $(0.04)$ & $(47.57)$ & $(487.63)$ & $(266.57)$ & $(0.43)$ \\
& 0.0023 & -0.0074 & 0.3341 & & & & \\
NEP & $(0.01)$ & $(0.09)$ & $(0.32)$ & - & - & - & - \\
& -0.0001 & $0.1770^{* *}$ & 0.0101 & $-1.1792^{* *}$ & 1.1152 & 0.2928 & $0.9097^{* *}$ \\
PAK & $(0.00)$ & $(0.07)$ & $(0.02)$ & $(0.41)$ & $(0.81)$ & $(0.25)$ & $(0.04)$ \\
& -0.0006 & $0.2936^{* *}$ & 0.0255 & -3.6150 & 13.5762 & 0.7313 & 0.0177 \\
SRI & $(0.00)$ & $(0.07)$ & $(0.03)$ & $(371.23)$ & $(2566.67)$ & $(138.01)$ & $(0.29)$ \\
\hline
\end{tabular}

Notes: The table summarizes the AR (1) estimation results for Bangladesh and Nepal, and EGARCH $(1,1)$ estimation results for India, Pakistan and Sri Lanka. 1) Figures in ( ) includes standard error. ${ }^{* *}$ indicates significance at $5 \%$ level of significance; 2) $R_{\text {countryi, }}$ and $R_{\text {asia,t }}$ denote country is short term debt returns and US short term debt returns respectively; 3) Coefficient $\omega$ measures the constant term; Coefficient $Y$ measures leverage effect while Coefficient $\beta$ measures persistence (GARCH effect). Source: Authors' calculations. 
(b)

\begin{tabular}{cccccccc}
\hline \multicolumn{3}{c}{ Mean Eqn } & \multicolumn{7}{c}{ Variance Eqn } \\
\hline Country & $\boldsymbol{\mu}$ & $\boldsymbol{R}_{\text {country I }}(-1)$ & $\boldsymbol{R}_{\mathrm{USA}}(-1)$ & $\boldsymbol{\omega}$ & $\boldsymbol{\alpha}$ & $\boldsymbol{\gamma}$ & $\boldsymbol{\beta}$ \\
\hline \multirow{2}{*}{ BANG } & 0.0502 & -0.0213 & 0.0208 & - & - & - & - \\
& $(0.04)$ & $(0.10)$ & $(0.06)$ & - & & & \\
& -0.0056 & 0.0091 & $0.0721^{\star *}$ & $0.8793^{\star *}$ & $0.6640^{\star *}$ & -0.0078 & $0.8412^{\star *}$ \\
IND & $(0.02)$ & $(0.09)$ & $(0.03)$ & $(0.37)$ & $(0.25)$ & $(0.12)$ & $(0.11)$ \\
& 0.0094 & -0.0191 & -0.0042 & & & & - \\
NEP & $(0.01)$ & $(0.08)$ & $(0.01)$ & - & - & - & - \\
& -0.0015 & 0.0557 & 0.0267 & & & & \\
PAK & $(0.04)$ & $(0.08)$ & $(0.06)$ & - & - & - & - \\
& -0.0066 & 0.0269 & -0.0584 & & & & \\
SRI & $(0.05)$ & $(0.08)$ & $(0.07)$ & - & - & - & - \\
& & &
\end{tabular}

Notes: The table summarizes the AR (1) estimation results for Bangladesh, Nepal, Pakistan and Sri Lanka, and EGARCH $(1,1)$ estimation results for India. 1) Figures in ( ) includes standard error. ${ }^{* *}$ indicates significance at $5 \%$ level of significance; 2) $\mathrm{R}_{\text {countryit, }}$ and $\mathrm{R}_{\text {asia,t }}$ denote country $i$ s long term debt returns and US long term debt returns respectively; 3) Coefficient $\omega$ measures the constant term; Coefficient $\gamma$ measures leverage effect while Coefficient $\beta$ measures persistence (GARCH effect). Source: Authors' calculations.

significant only for India implying presence of interlinkages between the long-term returns of India and the US. Further, results display presence of long run volatility persistence (measured by $\beta$ coefficient) in the short-term debt return series of Pakistan and long-term debt return series of India.

We obtain residuals for all short and long term return series from their respective marginal model. These residuals, found to be approximately i.i.d (independently and identically distributed), are converted into their uniform variates using cumulative distribution function. We now turn to employ copula models to estimate pair wise dependence parameters between 1) short term debt returns of South Asian countries, 2) long term debt returns of South Asian countries and 3) short and long term debt returns for each South Asian country.

\subsubsection{Time Invariant Copula Results}

Estimation results of time invariant copula models are reported in Table 3(a) and Table 3(b). Elliptical family of copula (Gaussian and Student-t) appear to be the best fit for majority of the country pairs in both short and long term debt markets, as indicated by lowest negative log-likelihood values. Results demonstrate that both short and long term debt markets of the South Asian region exhibit weak dependencies as indicated by low value of dependence parameters for majority of the country pairs. Trade integration between the countries, which is regarded as an important factor reinforcing cross-country linkages in capital markets [5], is poor among the South Asian countries as highlighted by [53]; hence it can plausibly be the reason for low level of debt market linkages in the region. Low level of integration can also be ascribed to varied macroeconomic performance and, high and unstable inflation thereby hampering their intraregional links. Further, weak governance parameters [53] has impeded the integration across the debt markets which is clearly reflected in the low level of short 
Table 3. (a): Estimation Results of Time Invariant Copula Models of Dependence amongst Short term Debt markets of sample countries; (b): Estimation Results of Time Invariant Copula Models of Dependence amongst Long term Debt markets of sample countries.

(a)

\begin{tabular}{cccccccccc}
\hline & \multicolumn{4}{c}{ Normal } & \multicolumn{2}{c}{ Clayton } & \multicolumn{2}{c}{ Gumbel } & \multicolumn{2}{c}{ Student t } \\
\hline & & Value & LL & Value & LL & Value & LL & Value & LL \\
\hline BANG & IND & 0.11 & -0.65 & 0.04 & -0.04 & 1.10 & -0.51 & 0.11 & -0.61 \\
BANG & NEP & 0.10 & -0.64 & 0.10 & -0.35 & 1.10 & -1.90 & 0.08 & -2.75 \\
BANG & PAK & 0.03 & -0.04 & 0.06 & -0.15 & 1.10 & 0.79 & 0.02 & -0.43 \\
BANG & SRI & 0.01 & -0.01 & 0.00 & 0.00 & 1.10 & 1.08 & 0.02 & 0.03 \\
IND & NEP & -0.05 & -0.20 & 0.00 & 0.00 & 1.10 & 3.00 & -0.05 & -0.16 \\
IND & PAK & 0.09 & -0.58 & 0.19 & -1.79 & 1.10 & 0.88 & 0.09 & -0.86 \\
IND & SRI & 0.07 & -0.40 & 0.03 & -0.03 & 1.10 & 0.38 & 0.08 & -0.29 \\
NEP & PAK & 0.21 & -3.27 & 0.19 & -1.56 & 1.16 & -4.05 & 0.21 & -3.39 \\
NEP & SRI & 0.03 & -0.05 & 0.12 & -0.89 & 1.10 & 1.71 & -0.03 & -1.13 \\
PAK & SRI & 0.14 & -1.48 & 0.18 & -1.49 & 1.10 & -0.32 & 0.15 & -1.34 \\
\hline
\end{tabular}

Notes: The table summarizes the time invariant copula estimation results. 1) Value denotes the dependence parameter between the sample country short term debt returns with each other using the different copula models; 2) LL denotes the log likelihood value of the dependence parameter between sample countries short term debt returns with each other using the different copula models; 3) Value in bold denotes lowest negative log likelihood thereby providing the best fit copula model amongst the family of models under study. Source: Authors' calculations.

(b)

\begin{tabular}{cccccccccc}
\hline & \multicolumn{4}{c}{ Normal } & \multicolumn{2}{c}{ Clayton } & \multicolumn{2}{c}{ Gumbel } & \multicolumn{2}{c}{ Student t } \\
\hline & & Value & LL & Value & LL & Value & LL & Value & LL \\
\hline BANG & IND & -0.10 & -0.63 & 0.00 & 0.00 & 1.10 & 2.54 & -0.11 & -0.49 \\
BANG & NEP & -0.26 & -4.04 & 0.00 & 0.00 & 1.10 & 4.47 & -0.30 & -4.45 \\
BANG & PAK & 0.15 & -1.31 & 0.11 & -0.36 & 1.10 & -1.11 & 0.16 & -1.23 \\
BANG & SRI & 0.19 & -2.05 & 0.32 & -3.19 & 1.12 & -1.53 & 0.18 & -2.91 \\
IND & NEP & 0.05 & -0.16 & 0.03 & -0.05 & 1.10 & 0.25 & 0.05 & -0.16 \\
IND & PAK & 0.08 & -0.47 & 0.20 & -1.81 & 1.10 & 0.83 & 0.08 & -0.84 \\
IND & SRI & 0.00 & 0.00 & 0.00 & 0.00 & 1.10 & 0.00 & 0.02 & -0.59 \\
NEP & PAK & -0.24 & -4.37 & 0.00 & 0.01 & 1.10 & 5.07 & -0.32 & -7.10 \\
NEP & SRI & 0.05 & -0.17 & 0.09 & -0.33 & 1.10 & 0.52 & 0.09 & -0.90 \\
PAK & SRI & 0.01 & 0.00 & 0.00 & 0.00 & 1.10 & 1.02 & 0.01 & 0.04 \\
\hline
\end{tabular}

Notes: The table summarizes the time invariant copula estimation results. 1) Value denotes the dependence parameter between the sample country long term debt returns with each other using the different copula models; 2) LL denotes the log likelihood value of the dependence parameter between sample countries long term debt returns with each other using the different copula models; 3) Value in bold denotes lowest negative log likelihood thereby providing the best fit copula model amongst the family of models under study. Source: Authors' calculations.

and long term debt inflows into the SAARC region compared to its ASEAN counterpart ${ }^{9}$. India seems to have relatively strong association with Bangladesh.

${ }^{9}$ The level of short and long term debt inflows into the SAARC region amounted to USD 23bn and 77bn respectively in 2015, which are low as compared its ASEAN counterpart with inflows amounting to USD 36bn for short-term debt and USD 252bn for long-term debt (source: IMF CPIS). 
This is not surprising given the development assistance extended by India to Bangladesh in form of line of credit worth USD 1billion in 2010 which has boosted bilateral relations between the countries and has provided impetus to trade and financial integration between the countries. An interesting characteristic of the long term debt markets of the region, as revealed by our empirical results, is that the level of dependency of India with other South Asian members is relatively low than that of other countries amongst themselves. Dependency is found to be particularly high between Bangladesh-Nepal and Nepal-Pakistan. This can be attributed to China's growing presence in the South Asian region, transcending India as the major player in the region in terms of trade and investment links with other South Asian countries ${ }^{10}$. Thus, relatively high association amongst the long term debt markets of the South Asian countries (except India) seem to be reflected in China's massive trading and investment in these countries. In case of short term debt markets of the region, highest interdependence is found between Nepal and Pakistan. The degree of integration at the short end is dictated by business cycle synchronization across the countries [5] [6] [21]. Thus, the level of GDP growth of the two countries can possibly be the determining factor as the two countries have been, on an average, growing at a similar rate of $4.1 \%$ over the last 10 years (from 2005-2015, source: WDI). The dependencies between the short and long term debt market for the South Asian countries computed from time invariant copula models are presented in Table 4. Except the debt market of Nepal, all countries have moderately high associations (above 0.30) between their short term and long term debt markets. The dependence parameter for Nepal is -0.05 indicating weak linkages between its short and long term markets which can be attributed to its changing political scenario.

\subsubsection{Time Varying Copula Results}

Figure 3 and Figure 4 depict the results relating to the time varying pairwise dependence measure between the short term and long term South Asian debt markets, respectively. In order to check the quality of the overall fit of the family of copula models, goodness of fit test of [45] is applied on the uniform variates obtained from the standardized residuals of the marginal specification to find the $p$-values associated with the test statistics. Highest $p$ value provides the best fit copula model amongst the different family of models used. We have charted the best fit time varying copula model so selected from the goodness of fit test (Refer Table 5(a) and Table 5(b)) against its corresponding time invariant copula parameter to study its inter temporal dependence. The dynamic evolution of dependences for both short and long term debt market returns of sample

${ }^{10}$ China has surpassed India as the largest FDI contributor to Nepal with several infrastructure and energy projects being financed by it in Nepal. Investment of China in Bangladesh is surging in the recent years. China has even signed USD 24 billion credit agreement with Bangladesh recently. China-Pakistan Economic Corridor is an ambitious project of China and Pakistan that will boost investment links between the countries. Further, China has taken lead in investing in Sri Lanka by providing financial assistance in infrastructure projects like building highways, ports and airport. 
Table 4. Estimation Results of Time Invariant Copula Models of Dependence between Short and Long term Debt markets of sample countries.

\begin{tabular}{ccccccccc}
\hline & \multicolumn{2}{c}{ Normal } & \multicolumn{2}{c}{ Clayton } & \multicolumn{2}{c}{ Gumbel } & \multicolumn{2}{c}{ Student t } \\
\hline & Value & LL & Value & LL & Value & LL & Value & LL \\
\hline BANG & 0.29 & -4.46 & 0.50 & -6.23 & 1.19 & -3.05 & 0.30 & -4.53 \\
IND & 0.35 & -9.92 & 0.59 & -11.17 & 1.30 & -10.51 & 0.35 & -15.32 \\
NEP & -0.05 & -0.18 & 0.00 & 0.00 & 1.10 & 1.61 & -0.05 & -1.28 \\
PAK & 0.30 & -6.53 & 0.55 & -10.25 & 1.21 & -4.55 & 0.31 & -7.91 \\
SRI & 0.40 & -12.18 & 0.67 & -13.15 & 1.36 & -11.40 & 0.44 & -14.70 \\
\hline
\end{tabular}

Notes: The table summarizes the time invariant copula estimation results. 1) Value denotes the dependence parameter between the short and long term debt returns of the sample countries using the different copula models; 2) LL denotes the log likelihood value of the dependence parameter between short and long term debt returns of sample countries using the different copula models; 3) Value in bold denotes lowest negative $\log$ likelihood thereby providing the best fit copula model amongst the family of models under study. Source: Authors' calculations.

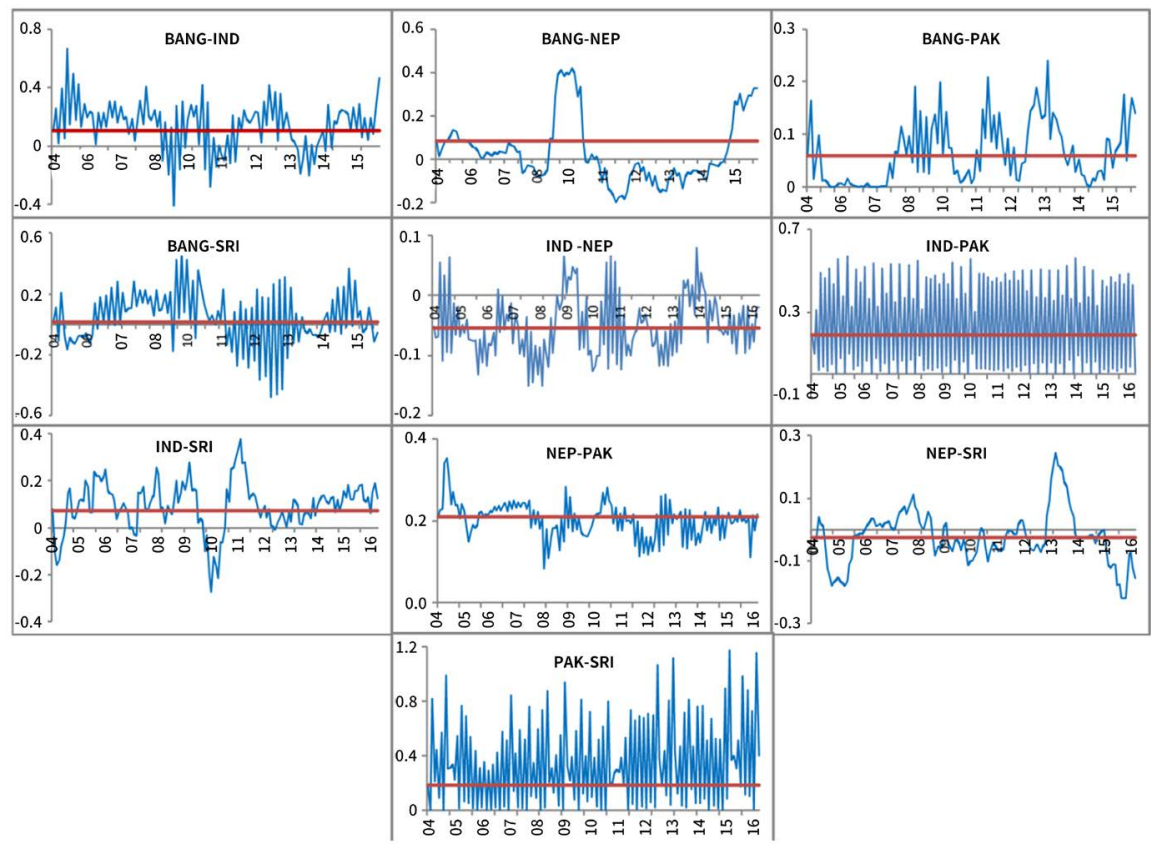

Figure 3. Time varying Copula Models-Pairwise Dependences between short term debt returns of sample countries. Note: The best fit time varying copula model selected by the goodness of fit test for different family of copula models plotted along with its corresponding time invariant dependency measure (in red line). Source: Authors' calculations.

countries seems to be volatile for majority of the period under study. It is clearly reflected that the integration among the countries has remained immune to the volatility unleashed by Global Financial Crisis of 2008 as the dependences remain persistently volatile for the entire period and no visible divergences in the pattern are observed during and post the crisis. This seems to imply regional and global segmentation of the South Asian debt markets as they are weakly integrated with each other as well as insulated from the global shocks. The goodness 


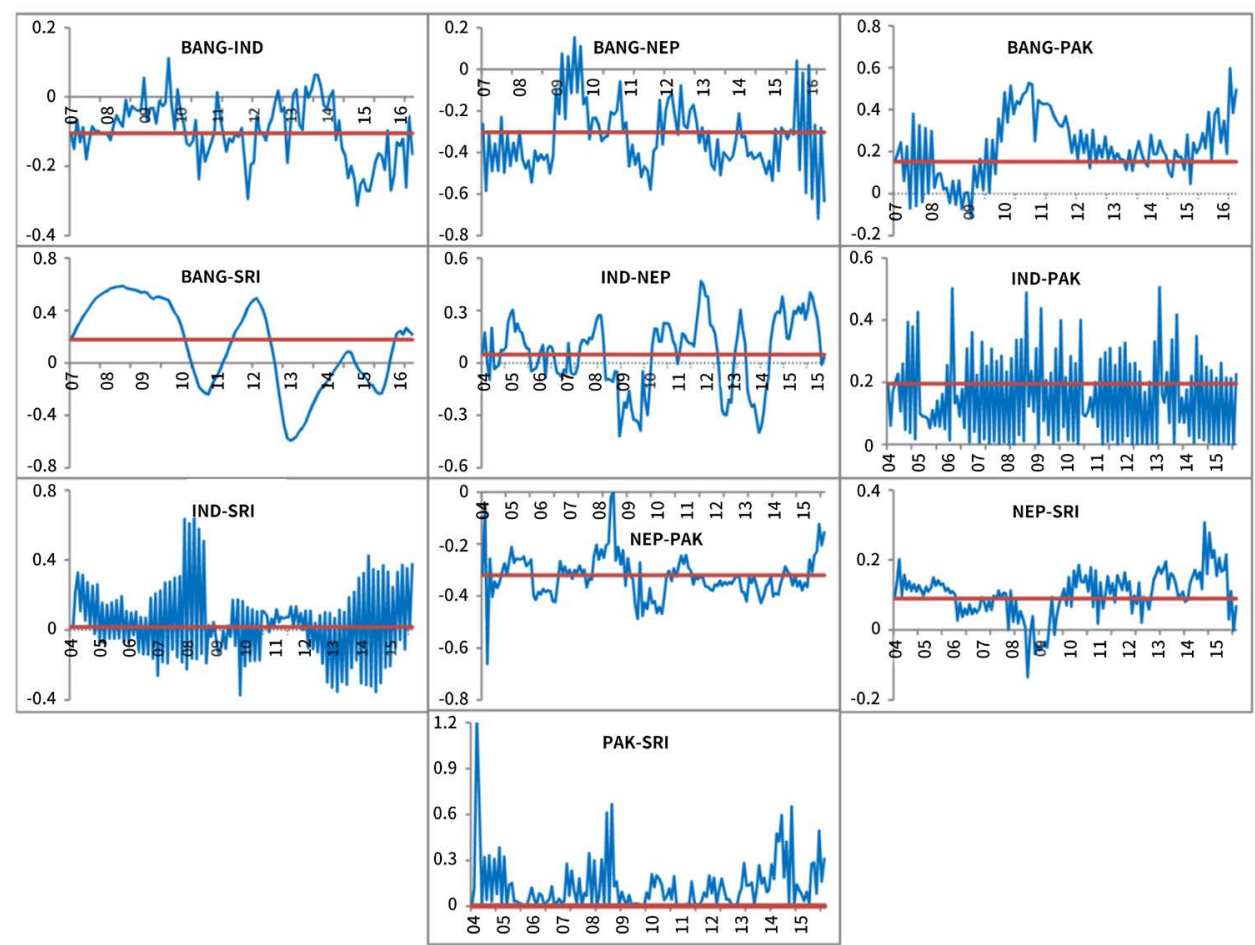

Figure 4. Time varying Copula Models-Pairwise Dependences between long term debt returns of sample countries. Note: The best fit time varying copula model selected by the goodness of fit test for different family of copula models plotted along with its corresponding time invariant dependency measure (in red line). Source: Authors' calculations.

Table 5. (a): Goodness of Fit Test for different copula models of dependence amongst short term debt markets of sample countries; (b): Goodness of Fit Test for different copula models of dependence amongst long term debt markets of sample countries.

(a)

\begin{tabular}{ccccc}
\hline & & Normal & Clayton & Student-t \\
\hline BANG & IND & 0.20 & 0.05 & 0.17 \\
BANG & NEP & 0.62 & - & 0.73 \\
BANG & PAK & 0.82 & 0.88 & 0.74 \\
BANG & SRI & 0.89 & 0.79 & 0.88 \\
IND & NEP & 0.80 & 0.84 & 0.93 \\
IND & PAK & 0.56 & 0.89 & 0.56 \\
IND & SRI & 0.06 & 0.04 & 0.04 \\
NEP & PAK & 0.40 & 0.24 & 0.51 \\
NEP & SRI & 0.15 & 0.06 & 0.29 \\
PAK & SRI & 0.52 & 0.67 & 0.32 \\
\hline
\end{tabular}

Notes: The table presents the p-values of the goodness-of-fit test for different copula models of dependence amongst short term debt markets of sample countries. 1) Large p-values (bold face numbers) indicate that the copula provides best fit to the data; 2) Goodness of fit test could not be estimated for time varying Gumbel Copula model as it exhibits upper tail dependence, indicating that large positive joint extreme events are more likely to occur than large negative ones and the given sample series has dependences which are close to 0. Source: Authors' calculations. 
(b)

\begin{tabular}{lcccc}
\hline & & Normal & Clayton & Student-t \\
\hline BANG & IND & 0.05 & - & 0.03 \\
BANG & NEP & 0.00 & - & 0.00 \\
BANG & PAK & 0.04 & 0.02 & 0.01 \\
BANG & SRI & 0.19 & 0.18 & 0.32 \\
IND & NEP & 0.98 & - & 0.92 \\
IND & PAK & 0.27 & 0.65 & 0.25 \\
IND & SRI & 0.05 & - & 0.13 \\
NEP & PAK & 0.00 & - & 0.00 \\
NEP & SRI & 0.00 & 0.03 & 0.05 \\
PAK & SRI & 0.21 & 0.25 & 0.08 \\
\hline
\end{tabular}

Notes: The table presents the p-values of the goodness-of-fit test for different copula models of dependence amongst long term debt markets of sample countries. 1) Large p-values (bold face numbers) indicate that the copula provides best fit to the data; 2) Goodness of fit test could not be estimated for time varying Gumbel Copula model as it exhibits upper tail dependence, indicating that large positive joint extreme events are more likely to occur than large negative ones and the given sample series has dependences which are close to 0 . Source: Authors' calculations.

of fit test in case of both short and long term debt market seems to select mainly Gaussian family of copula model over Archimedean family which shows that given how dormant these markets are in this region, debt market association are normally distributed. Contrary to expectations that the goodness of fit test for debt market co-movements would again select the Clayton copula family similar to that for equity and currency asset class for the same region [53] [54], the nature of the markets per se gives ample evidence of the fact that the debt markets of the region are underdeveloped.

Figure 5 illustrates the dynamic dependence parameter between short and long term of debt market returns of sample countries. The best fit time-varying copula model is selected from the goodness of fit test (refer Table 6) against its time invariant copula parameter. The sense of a strong and relatively mature Indian debt markets can be seen from the figure which shows the low volatility but an equilibrium relationship of the dependences between long and short term of the debt market co-movement. The robustness of the copula results are confirmed when the choice of copula model selected doesn't change when one uses raw returns or filtered returns (residuals). The goodness of fit test which was run on the raw returns ${ }^{11}$ also selected the same copula model as was selected when residuals were used. The copula parameter estimation and testing methodology would not be suffering from statistical biases when residuals are used as they are i.i.d.

\subsection{Estimation Results of Diebold and Yilmaz Spillover Index}

Having estimated the dependence structure among the South Asian debt

${ }^{11}$ Results not presented here due to brevity of space but can be available on request by the authors. 


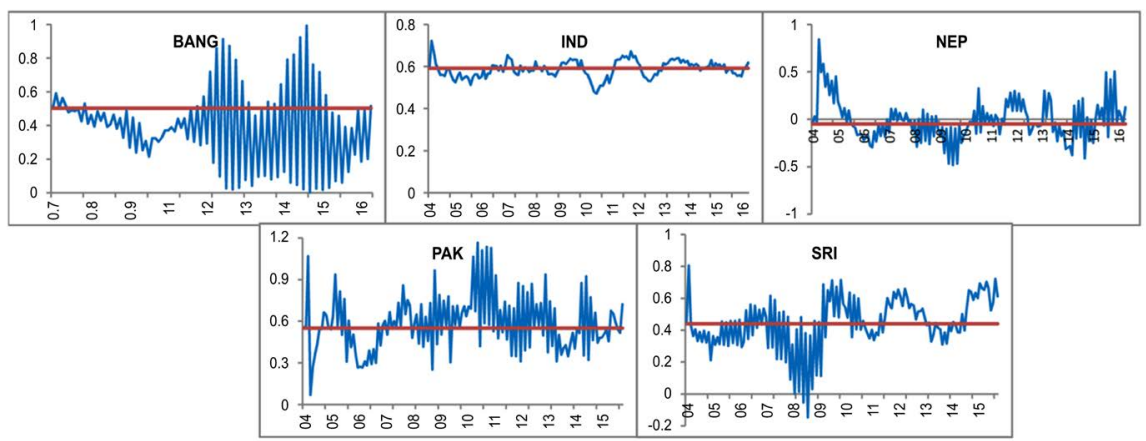

Figure 5. Time varying Copula Models-Dependences between short and long term debt returns of sample countries. Note: The best fit time varying copula model selected by the goodness of fit test for different family of copula models plotted along with its corresponding time invariant dependency measure (in red line). Source: Authors' calculations.

Table 6. Goodness of Fit Test for different copula models of dependence between short and long term debt markets of sample countries.

\begin{tabular}{cccc}
\hline & Normal & Clayton & Student-t \\
\hline BANG & 0.31 & 0.85 & 0.32 \\
IND & 0.33 & 0.46 & 0.43 \\
NEP & 0.91 & - & 0.99 \\
PAK & 0.35 & 0.97 & 0.51 \\
SRI & 0.26 & 0.02 & 0.51 \\
\hline
\end{tabular}

Notes: The table presents the p-values of the goodness-of-fit test for different copula models of dependence between short and long term debt markets of sample countries. 1) Large p-values (bold face numbers) indicate that the copula provides best fit to the data; 2) Goodness of fit test could not be estimated for time varying Gumbel Copula model as it exhibits upper tail dependence, indicating that large positive joint extreme events are more likely to occur than large negative ones and the given sample series has dependences which are close to 0 . Source: Authors' calculations.

markets using copula functions, we now turn to examine their integration by ascertaining the level of transmission of shocks from one market to another using Diebold and Yilmaz [7] spillover index. While copulas provide only the estimates of conditional correlation, this methodology allows us to quantify the cross-market directional spillovers thereby giving further insights into the level of financial linkages in the South Asian debt markets. We compute return spillover indices by employing Diebold and Yilmaz [7] spillover index methodology for 1) short term debt markets across the South Asian countries, 2) long term debt markets of the sample countries, and 3) short and long term debt market within each sample country. Long term debt returns of Nepal were persistently zero corresponding to that of other countries for the entire period; hence it could not be included in the study. The results are based on vector autoregression lag specification of order 3 and generalized variance decomposition of 3 months ahead forecast variance. We are not able to estimate the time-varying spillover indices using rolling window estimation because the debt returns of Bangladesh, Nepal and Pakistan are zero for long stretches of time. Table 7(a) 
Table 7. (a): Diebold and Yilmaz Spillover Summary Results for Short term Debt Markets of South Asian Countries; (b): Diebold and Yilmaz Spillover Summary Results for Long term Debt Markets of South Asian Countries.

(a)

\begin{tabular}{ccccccc}
\hline & BANG & IND & NEP & PAK & SRI & From Others \\
\hline BANG & 83.07 & 7.88 & 0.52 & 5.28 & 3.25 & 16.90 \\
IND & 2.69 & 92.99 & 1.37 & 0.88 & 2.08 & 7.00 \\
NEP & 2.10 & 3.51 & 86.86 & 6.89 & 0.63 & 13.10 \\
PAK & 0.96 & 2.39 & 5.92 & 89.81 & 0.93 & 10.20 \\
SRI & 4.30 & 5.19 & 1.13 & 1.69 & 87.69 & 12.30 \\
Contribution to & 10.10 & 19.00 & 8.90 & 14.70 & 6.90 & 59.60 \\
others & & & & & & $11.90 \%$ \\
$\begin{array}{c}\text { Contribution } \\
\text { including own }\end{array}$ & 93.10 & 111.90 & 95.80 & 104.50 & 94.60 & \\
\hline
\end{tabular}

Notes: The table presents Diebold and Yilmaz (2012) Spillover table summary for short term debt markets of South Asian countries. 1) The diagonal entries of the matrix represent the own variance share of the sample countries and the off-diagonal elements show the cross-market spillovers; 2) The last column of the matrix ("from others") highlights the gross directional return spillovers to the country from rest of the countries; 3) The second last row ("to others") indicates the gross directional spillover from a country to rest of the countries. Source: Authors' calculations.

(b)

\begin{tabular}{cccccc}
\hline & BANG & IND & PAK & SRI & From others \\
\hline BANG & 94.26 & 0.58 & 4.94 & 0.22 & 5.70 \\
IND & 0.71 & 90.71 & 4.95 & 3.62 & 9.30 \\
PAK & 9.10 & 7.59 & 78.21 & 5.10 & 21.80 \\
SRI & 3.49 & 1.71 & 2.47 & 92.33 & 7.70 \\
$\begin{array}{c}\text { Contribution to } \\
\text { others }\end{array}$ & 13.30 & 9.90 & 12.40 & 8.90 & 44.50 \\
$\begin{array}{c}\text { Contribution } \\
\text { including own }\end{array}$ & 107.60 & 100.60 & 90.60 & 101.30 & $11.10 \%$ \\
\hline
\end{tabular}

Notes: The table presents Diebold and Yilmaz (2012) Spillover table summary for short term debt markets of South Asian countries. 1) The diagonal entries of the matrix represent the own variance share of the sample countries and the off-diagonal elements show the cross-market spillovers; 2) The last column of the matrix ("from others") highlights the gross directional return spillovers to the country from rest of the countries; 3) The second last row ("to others") indicates the gross directional spillover from a country to rest of the countries. Source: Authors' calculations.

and Table 7(b) present the time aggregated short term and long term debt return spillovers matrix, respectively. The diagonal entries of the matrix represent the own variance share of the sample countries and the off-diagonal elements show the cross-market spillovers i.e. contribution to the forecast error variance of country $i$ coming from shocks to country $j$. The last column of the matrix ("from others") highlights the gross directional volatility spillovers to the country from rest of the countries. The second last row ("to others") indicates the gross directional spillover from a country to rest of the countries.

The total return spillover (bottom right corner of the matrix) across the 
short-term and long-term debt markets of South Asian countries is on an average $11.9 \%$ and $11.10 \%$, respectively indicating that the debt markets of these countries are not much influential in transmitting shocks to the region. This can be due to limited cross-border trade and investment in the South Asian countries as spillovers are mainly propagated through trade and financial channels. Low return spillover across both short and long term debt markets of the region corroborates copula results which demonstrate low level of dependencies amongst the debt markets of majority of the country pairs of the region, thereby implying low level of financial integration in the South Asian region.

As can be seen from Table 7(a) and Table 7(b), the own variance shares of both short and long term debt markets of all countries are inordinately high implying that the contribution to their forecast error variance result mainly from the innovations in the own market rather than from other markets of the region. The debt markets of these countries are not receptive to the shocks from the region as indicated by the low gross directional spillover index of both short and long term markets and thus operate independently of each other.

The level of connectedness of short term debt market of India, as reflected by the pairwise gross directional spillovers (to and from), is highest with that of Bangladesh as compared to the short term debt market of any other South Asian economy. This implies that the short term debt markets of these two countries are strongly linked with each other, with India being the net transmitter. As noted above (refer section 4.2.1), this is due to the line of credit granted by India to Bangladesh in 2010. With additional line of credit extended recently by India to Bangladesh worth USD 2 billion that is so far the highest credit extended by India, the bilateral trade and financial links between the two countries is expected to take a leap in future which might be reflected in enhanced linkages in their short as well as long term debt markets. It is noteworthy to point here that India is the chief net transmitter of spillovers in the entire region. This can be attributed to the size and depth of the Indian debt market that is third largest in Asia after China and Korea and has grown at a compounded annual (outstanding local currency bonds) growth rate of $10.6 \%$ between 2005 and 2015 [55].

Relatively strong connectedness of the short term debt markets of Nepal and Pakistan is reflected in the pairwise directional spillover index, with Nepal contributing $5.92 \%$ to forecast error variance of Pakistan and receiving $6.89 \%$ spillovers from it. This strengthens copula results that also revealed strong dependences between the short term debt markets of the two countries. In case of long term debt markets, Bangladesh and Pakistan are financially more interlinked as the pairwise gross spillover across these two countries is highest. Linkages between the two countries are probably an outcome of rising Chinese influence in their economies especially through its long-term investment. High interconnectedness is also observable between India and Pakistan possibly due to their relatively developed debt markets with public bonds outstanding close to $30 \%$ of their GDP [1]. 
Time aggregated spillover matrices of all sample countries representing the linkages between their short and long term debt markets are presented in Table 8. While copula estimates reveal moderate associations of short and long term debt markets within the South Asian countries (except Nepal), total spillovers index of each country provides ample evidence of weak linkages between their debt markets of differing maturities. Lack of integration between the short and long term debt markets of the sample countries reflects heterogeneity of investors in targeting different maturity segments, which probably leads to market

Table 8. Diebold and Yilmaz Spillover summary results for short and long term debt market of sample countries.

\begin{tabular}{|c|c|c|c|}
\hline BANG & Short term & Long term & From others \\
\hline Short term & 94.49 & 5.51 & 5.50 \\
\hline Long term & 6.30 & 93.70 & 6.30 \\
\hline Contribution to others & 6.30 & 5.50 & 11.80 \\
\hline Contribution including own & 100.80 & 99.20 & $5.90 \%$ \\
\hline IND & Short term & Long term & From Others \\
\hline Short term & 85.61 & 14.39 & 14.40 \\
\hline Long term & 13.83 & 86.17 & 13.80 \\
\hline Contribution to others & 13.80 & 14.40 & 28.20 \\
\hline Contribution including own & 99.40 & 100.60 & $14.10 \%$ \\
\hline NEP & Short term & Long term & From Others \\
\hline Short term & 98.86 & 1.14 & 1.10 \\
\hline Long term & 1.08 & 98.92 & 1.10 \\
\hline Contribution to others & 1.10 & 1.10 & 2.20 \\
\hline Contribution including own & 99.90 & 100.10 & $1.10 \%$ \\
\hline PAK & Short term & Long term & From Others \\
\hline Short term & 90.94 & 9.06 & 9.10 \\
\hline Long term & 11.48 & 88.52 & 11.50 \\
\hline Contribution to others & 11.50 & 9.10 & 20.50 \\
\hline Contribution including own & 102.40 & 97.60 & $10.30 \%$ \\
\hline SRI & Short term & Long term & From Others \\
\hline Short term & 79.16 & 20.84 & 20.80 \\
\hline Long term & 17.33 & 82.67 & 17.30 \\
\hline Contribution to others & 17.30 & 20.80 & 38.20 \\
\hline Contribution including own & 96.50 & 103.50 & $19.10 \%$ \\
\hline
\end{tabular}

Notes: The table presents Diebold and Yilmaz (2012) Spillover matrices for all sample countries indicating spillovers across their short and long term debt markets. 1) The diagonal entries of the matrix represent the own variance share of the sample country market and the off-diagonal elements show the cross-market spillovers; 2) The last column of the matrix ("from others") highlights the gross directional return spillovers to one debt market from another; 3) The second last row ("to others") indicates the gross directional spillover from one debt market to another. Source: Authors' calculations. 
segmentation based on maturity. This clearly highlights the fact that there is a lack of progress in the development of debt markets of these economies, may be due to idiosyncratic factors such as credit and/or liquidity risks as well as primitive stage of development of their debt markets.

\section{Summary and Policy Suggestions}

In this paper, we investigate the extent of financial integration in both short and long term debt markets amongst the five economies of South Asian region (Bangladesh, India, Nepal, Pakistan and Sri Lanka). We also explore interlinkages in the short and long debt markets within these countries. The study uses 91-day Treasury bill and 10-year government securities yields as a proxy for short and long term yields, respectively over the period January 2004 to May 2016. Copula functions are employed to ascertain the pairwise dependence structures of the countries. We further supplement our analysis using Diebold and Yilmaz [7] spillover index to ascertain the level of transmission of shocks from one market to another. While copulas provide only the estimates of conditional correlation, this methodology allows us to quantify the cross-market directional spillovers thereby giving further insights into the level of financial linkages in the South Asian debt markets. Our results demonstrate low level of financial integration in both short and long term debt markets of the South Asian region. Low level of debt market integration can be ascribed to limited cross-border trade and investment, varied macroeconomic performance and weak governance parameters of the countries. In case of long term debt markets, we find that the level of dependency of India with other South Asian members is relatively low than that of other countries amongst themselves. Dependency is found to be particularly high between Bangladesh-Nepal and Nepal-Pakistan, which can be attributed to China's growing presence in the South Asian region, transcending India as the major player in the region in terms of trade and investment links with other South Asian countries. Amongst the short term debt markets, the highest interdependence is found between Nepal and Pakistan, possibly due to their economic convergence over the last 10 years. India, which has the most developed debt market of the South Asian region, has relatively strong linkages with Bangladesh plausibly due to the line of credit worth USD 1 billion extended by India to Bangladesh in 2010. High interconnected is also observable between India and Pakistan which seems to be reflected in their relatively developed debt markets with public bonds outstanding close to $30 \%$ of their GDP. Time varying results seem to suggest that global insulation of the South Asian debt markets as the dependencies amongst them remains immune to the volatility unleashed by Global Financial Crisis of 2008. Linkages between the short and long term debt markets of the South Asian countries are found to be weak suggesting lack of progress in the development of debt markets of these economies, which may be due to idiosyncratic factors such as credit and/or liquidity risks as well as primitive stage of development of their debt markets. 
The study has important implications for international investors, policymakers and academia. Low level of debt market integration among the South Asian countries indicates potential diversification opportunities for global investors. Long term debt securities inflows in the region are predominantly directed towards India indicating that India is considered to be the most attractive investment destination of the region by global investors. Global investors, therefore, can reap benefits by mobilizing their investments across the region and not particularly aligning it in one country. Policymakers of the region need to concede the importance of debt market linkages in promoting financial stability by insulating the economies from external headwinds. South Asian economies are predominantly driven by their bank based financial systems making them prone to financial crisis. Notwithstanding their resilience to the impact of Global Financial Crisis, these economies may not be able to sustain any future external shock in the wake of increased globalization. Therefore, policymakers need to foster cross-border trade investment flows that can provide basis for debt market integration amongst the countries. Further, they need to work on strengthening macroeconomic fundamentals and governance indicators to gain investors' confidence and foster monetary and credit policy coordination in the region. The reason why India has been able to stimulate debt inflows, which accounts for nearly $86 \%$ of the total debt inflows in the region ${ }^{12}$, is because of its accelerated economic growth and slew of debt market reforms introduced to advance market development, enhance participation and facilitate liquidity that have reverberated positive outlook of its market. South Asian countries need to develop their debt market infrastructure by liberalizing their listing requirements and simplification of procedures and processes to broaden the participation base in these markets. India, being the biggest country in terms of debt markets in the region, can come up with local currency debt issuance which must be accessible to other South Asian members to increase regional debt market integration. For an efficient and effective debt market to flourish in the region, member countries should also strive to introduce debt market derivatives i.e. Credit Default Swaps and Interest rate derivatives going forward. Taking lessons from India, other South Asian countries need to begin working upon their weak institutional and regulatory structures that defies their debt market development. India, being the largest country of the region, needs to steer the way towards monetary and credit policy cooperation amongst other member countries. South Asian countries can concentrate on the development of Government Securities markets and it is here wherein they can take domain expertise from India which has a well-regulated and functional government securities market, as monetary transmission mechanism depends upon term structure of interest rate. A consensus can be arrived amongst the member nations to develop the corporate bond markets in the long run wherein market infrastructure related aspects (allowing Foreign Portfolio Investments to invest, standardization of stamp duties etc.) could be worked

${ }^{12}$ Source: IMF CPIS, author's calculations. 
upon depending on each country's unique macroeconomic policy. The study contributes to limited literature on debt market integration of the South Asian countries. By focusing on both short and long term debt markets, the study offers useful insights by empirically examining the magnitude of financial integration of short as well as long term debt markets across the South Asian economies and between short and long term debt markets within the economies.

\section{Acknowledgements}

This manuscript is part of a sponsored research project entitled "Financial Integration in the SAARC Region: Empirical Analysis and Policy Issues". The authors would like to acknowledge the financial support provided by Indian Council of Social Sciences Research (ICSSR). We also thank the journal editor and the anonymous reviewer for their valuable inputs and suggestions that helped in improving the paper.

\section{Conflicts of Interest}

The authors declare no conflicts of interest regarding the publication of this paper.

\section{References}

[1] Burger, J.D., Warnock, F.E. and Warnock, V.C. (2015) Bond Market Development in Developing Asia. Asian Development Bank Economics Working Paper Series No. 448. https://doi.org/10.2139/ssrn.2707539

[2] Abad, P., Chuliá, H. and Gómez-Puig, M. (2010) EMU and European Government Bond Market Integration. Journal of Banking \& Finance, 34, 2851-2860. https://doi.org/10.1016/j.jbankfin.2009.10.009

[3] World Bank (2015) South Asia Economic Focus, Spring 2015: Making the Most of Cheap Oil. World Bank, Washington, DC. https://openknowledge.worldbank.org/handle/10986/21735

[4] World Bank (2014) South Asia Regional Brief. http://www.worldbank.org/en/news/feature/2014/03/24/south-asia-regional-brief

[5] Kumar, M.S. and Okimoto, T. (2011) Dynamics of International Integration of Government Securities Markets. Journal of Banking and Finance, 35, 142-154. https://doi.org/10.1016/j.jbankfin.2010.07.019

[6] Yang, L. and Hamori, S. (2014) Dependence Structure between CEEC-3 and German Government Securities Markets. Journal of International Financial Markets, Institutions and Money, 29, 109-125. https://doi.org/10.1016/j.intfin.2013.12.003

[7] Diebold, F.X. and Yilmaz, K. (2012) Better to Give than to Receive: Predictive Directional Measurement of Volatility Spillovers. International Journal of Forecasting, 28, 57-66. https://doi.org/10.1016/j.ijforecast.2011.02.006

[8] Kim, S.J., Lucey, B.M. and Wu, E. (2006) Dynamics of Bond Market Integration between Established and Accession European Union Countries. Journal of International Financial Markets, Institutions and Money, 16, 41-56. https://doi.org/10.1016/j.intfin.2004.12.004

[9] Laopodis, N.T. (2008) Government Bond Market Integration within European Union. International Research Journal of Finance and Economics, 19, 56-76.

[10] Pozzi, L. and Wolswijk, G. (2012) The Time-Varying Integration of Euro Area 
Government Bond Markets. European Economic Review, 56, 36-53. https://doi.org/10.1016/j.euroecorev.2011.05.006

[11] Georgoutsos, D.A. and Migiakis, P.M. (2013) European Sovereign Bond Spreads: Financial Integration and Market Conditions. Applied Financial Economics, 23, 1609-1621. https://doi.org/10.1080/09603107.2013.842637

[12] Abad, P., Chuliá, H. and Gómez-Puig, M. (2014) Time-Varying Integration in European Government Bond Markets. European Financial Management, 20, 270-290. https://doi.org/10.1111/j.1468-036X.2011.00633.x

[13] Christiansen, C. (2014) Integration of European Bond Markets. Journal of Banking \& Finance, 42, 191-198. https://doi.org/10.1016/j.jbankfin.2014.01.022

[14] Cipollini, A., Coakley, J. and Lee, H. (2015) The European Sovereign Debt Market: From Integration to Segmentation. The European Journal of Finance, 21, 111-128. https://doi.org/10.1080/1351847X.2013.788535

[15] Deltuvaite, V. (2015) Investigation of Global Integration of the Central and Eastern European Countries Sovereign Bond Markets. Procedia Economics and Finance, 24, 182-191. https://doi.org/10.1016/S2212-5671(15)00643-7

[16] Gupta, P., Sehgal, S. and Deisting, F. (2015) Time-Varying Bond Market Integration in EMU. Journal of Economic Integration, 30, 708-760. https://doi.org/10.11130/jei.2015.30.4.708

[17] Yang, L. and Hamori, S. (2015) Interdependence between the Bond Markets of CEEC-3 and Germany: A Wavelet Coherence Analysis. The North American Journal of Economics and Finance, 32, 124-138. https://doi.org/10.1016/j.najef.2015.02.003

[18] Šimović, P.P., Tkalec, M., Vizek, M. and Lee, J. (2016) Time-Varying Integration of the Sovereign Bond Markets in European Post-Transition Economies. Journal of Empirical Finance, 36, 30-40. https://doi.org/10.1016/j.jempfin.2015.12.005

[19] Vo, X.V. (2009) International Financial Integration in Asian Bond Markets. Research in International Business and Finance, 23, 90-106. https://doi.org/10.1016/j.ribaf.2008.07.001

[20] Rughoo, A. and You, K. (2015) Asian Financial Integration: Global or Regional? Evidence from Money and Bond Markets. International Review of Financial Analysis, 48, 419-434. https://doi.org/10.1016/j.irfa.2015.03.007

[21] Sowmya, S., Prasanna, K. and Bhaduri, S. (2016) Linkages in the Term Structure of Interest Rates across Sovereign Bond Markets. Emerging Markets Review, 27, 118-139. https://doi.org/10.1016/j.ememar.2016.05.001

[22] Ciner, C. (2007) Dynamic Linkages between International Bond Markets. Journal of Multinational Financial Management, 17, 290-303. https://doi.org/10.1016/j.mulfin.2007.02.007

[23] Bekaert, G. and Harvey, C.R. (1995) Time-Varying World Market Integration. The Journal of Finance, 50, 403-444. https://doi.org/10.1111/j.1540-6261.1995.tb04790.x

[24] Barr, D.G. and Priestley, R. (2004) Expected Returns, Risk and the Integration of International Bond Markets. Journal of International Money and Finance, 23, 71-97. https://doi.org/10.1016/j.jimonfin.2003.10.005

[25] Engsted, T. and Tanggaard, C. (2007) The Comovement of US and German Bond Markets. International Review of Financial Analysis, 16, 172-182. https://doi.org/10.1016/j.irfa.2006.03.002

[26] Laopodis, N.T. (2010) Dynamic Linkages among Major Sovereign Bond Yields. The Journal of Fixed Income, 20, 74. https://doi.org/10.3905/jfi.2010.20.1.074 
[27] Piljak, V. (2013) Bond Markets Co-Movement Dynamics and Macroeconomic Factors: Evidence from Emerging and Frontier Markets. Emerging Markets Review, 17, 29-43. https://doi.org/10.1016/j.ememar.2013.08.001

[28] Piljak, V. and Swinkels, L. (2015) Frontier and Emerging Government Bond Markets. Emerging Markets Review.

[29] Patton, A.J. (2006) Modelling Asymmetric Exchange Rate Dependence. International Economic Review, 47, 527-556. https://doi.org/10.1111/j.1468-2354.2006.00387.x

[30] Rodriguez, J.C. (2007) Measuring Financial Contagion: A Copula Approach. Journal of Empirical Finance, 14, 401-423. https://doi.org/10.1016/j.jempfin.2006.07.002

[31] Longin, F. and Solnik, B. (2001) Extreme Correlation of International Equity Markets. The Journal of Finance, 56, 649-676. https://doi.org/10.1111/0022-1082.00340

[32] Poon, S.-H., Rockinger, M. and Tawn, J. (2004) Extreme Value Dependence in Financial Markets: Diagnostics, Models, and Financial Implications. The Review of Financial Studies, 17, 581-610. https://doi.org/10.1093/rfs/hhg058

[33] Christoffersen, P.F. (2012) Elements of Financial Risk Management. Academic Press, Cambridge.

[34] Patton, A.J. (2006b) Estimation of Multivariate Models for Time Series of Possibly Different Lengths. Journal of Applied Econometrics, 21, 147-173.

https://doi.org/10.1002/jae.865

[35] Sklar, A. (1959) Fonctions de répartition à n dimensions etleursmarges. Publications de P Institut de Statistique de Paris, 8, 229-231.

[36] Basher, S.A., Salem, N. and Hui, Z. (2014) Dependence Patterns across Gulf Arab Stock Markets: A Copula Approach. Journal of Multinational Financial Management, 25-26, 30-50. https://doi.org/10.1016/j.mulfin.2014.06.008

[37] Delatte, A.L. and Lopez, C. (2013) Commodity and Equity Markets: Some Stylized Facts from a Copula Approach. Journal of Banking \& Finance, 37, 5346-5356. https://doi.org/10.1016/j.jbankfin.2013.06.012

[38] Nelson, D.B. (1991) Conditional Heteroskedasticity in Asset Returns: A New Approach. Econometrica: Journal of the Econometric Society, 59, 347-370. https://doi.org/10.2307/2938260

[39] Kim, M.S. and Wang, S. (2006) On the Application of Stochastic Volatility Models. Computational Statistics \& Data Analysis, 51, 2210-2217. https://doi.org/10.1016/j.csda.2006.08.002

[40] Mandelbrot, B.B. (1963) The Variation of Certain Speculative Prices. Journal of Business, 36, 392-417. https://doi.org/10.1086/294632

[41] Bollerslev, T. (1987) A Conditionally Heteroskedastic Time Series Model for Speculative Prices and Rates of Return. Review of Economics and Statistics, 69, 542-547. https://doi.org/10.2307/1925546

[42] Fernandez, V. (2008) Copula-Based Measures of Dependence Structure in Assets Returns. Physica A: Statistical Mechanics and Its Applications, 387, 3615-3628. https://doi.org/10.1016/j.physa.2008.02.055

[43] Gumbel, E.J. (1960) Bivariate Exponential Distributions. Journal of the American Statistical Association, 55, 698-707. https://doi.org/10.1080/01621459.1960.10483368

[44] Clayton, D.G. (1978) A Model for Association in Bivariate Life Tables and Its Application in Epidemiological Studies of Familial Tendency in Chronic Disease Incidence. Biometrika, 65, 141-152. https://doi.org/10.1093/biomet/65.1.141 
[45] Genest, C., Rémillard, B. and Beaudoin, D. (2009) Goodness-of-Fit Tests for Copulas: A Review and a Power Study. Insurance: Mathematics and Economics, 44, 199-213. https://doi.org/10.1016/j.insmatheco.2007.10.005

[46] Kojadinovic, I. and Yan, J. (2011) A Goodness-of-Fit Test for Multivariate Multiparameter Copulas Based on Multiplier Central Limit Theorems. Statistics and Computing, 21, 17-30. https://doi.org/10.1007/s11222-009-9142-y

[47] Aloui, R., Hammoudeh, S. and Nguyen, D.K. (2013) A Time-Varying Copula to Oil and Stock Market Dependence: The Case of Transition Economies. Energy Economics, 39, 208-221. https://doi.org/10.1016/j.eneco.2013.04.012

[48] Koop, G., Pesaran, M.H. and Potter, S.M. (1996) Impulse Response Analysis in Nonlinear Multivariate Models. Journal of Econometrics, 74, 119-147. https://doi.org/10.1016/0304-4076(95)01753-4

[49] Pesaran, H.H. and Shin, Y. (1998) Generalized Impulse Response Analysis in Linear Multivariate Models. Economics Letters, 58, 17-29. https://doi.org/10.1016/S0165-1765(97)00214-0

[50] Dickey, D.A. and Fuller, W.A. (1979) Distribution of the Estimators for Autoregressive Time Series with a Unit Root. Journal of the American Statistical Association, 74, 427-431.

[51] Kwiatkowski, D., Phillips, P.C.D., Schmidt, P. and Shin, Y. (1992) Testing the Null Hypothesis of Stationarity against the Alternative of a Unit Root: How Sure Are We That Economic Time Series Have a Unit Root? Journal of Econometrics, 54, 159-178. https://doi.org/10.1016/0304-4076(92)90104-Y

[52] Phillips, C.B.P. and Perron, P. (1988) Testing for a Unit Root in Time Series Regression. Biometrika, 75, 335-346. https://doi.org/10.1093/biomet/75.2.335

[53] Sehgal, S., Pandey, P. and Deisting, F. (2018) Time Varying Integration amongst the South Asian Equity Markets: An Empirical Study. Cogent Economics \& Finance, 6.

[54] Sehgal, S., Pandey, P. and Deisting, F. (2017) Examining Dynamic Currency Linkages amongst South Asian Economies: An Empirical Study. Research in International Business and Finance, 42, 173-190.

[55] Park, C.Y. (2016) Developing Local Currency Bond Markets in Asia. Asian Development Bank Economics Working Paper Series No. 495.

https://doi.org/10.2139/ssrn.2856248 